\title{
REVISTA DO CENTRO DE CIÊNCIAS DA EDUCAÇÃO
}

Volume 39, n. 3 - p. 01 - 19, jul./set. 2021 - Florianópolis

\section{Andrea Brandão Lapa}

Universidade Federal de Santa

Catarina, UFSC

E-mail:decalapa@gmail.com

(iD) https://orcid.org/0000-0001-6073-4012

\section{Isabel Colucci Coelho}

Universidade Federal de Santa

Catarina, UFSC

E-mail: isabelcolucci@gmail.com

(iD) https://orcid.org/0000-0001-6081-3618

\section{Escola e internet: espaços de formação para a cidadania}

\section{Andrea Brandão Lapa Isabel Colucci Coelho}

\section{Resumo}

Diante da recente crise social causada pela pandemia da Covid-19, é tarefa urgente do campo revisitar fundamentos da educação na cultura digital, para potencializar uma perspectiva emancipadora da educação na atualidade. Apesar da promessa de ampliação democrática trazida pela internet e demais tecnologias digitais de informação e comunicação, ao que assistimos é uma reconfiguração da indústria cultural pela proliferação de discurso de ódio, fake news, marketing político digital, capitalismo de dados, entre outras violências nas redes digitais. A tarefa da pesquisa em educação no momento é refletir e enunciar os desafios postos pela integração de tecnologias na vida cotidiana enquanto procura espaços de possibilidade para a existência e formação crítica de cidadãos no contexto da cultura digital. $\mathrm{O}$ artigo elabora uma reflexão teórica para consolidar as bases de um outro paradigma de educação, baseado na educação em direitos humanos em uma escola conectada com o mundo. A partir de uma perspectiva crítica, propõe que a educação se ocupe da leitura crítica das mídias, mas também de experimentar formas de apropriação criativa que formem sujeitos como autores e produtores de sua história.

Palavras-chave: Educação para a cidadania. Tecnologia e Educação. Cultura Digital.
Recebido em: 05/03/2020

Aprovado em: 10/04/2021 


\section{Abstract}

Keywords: Public Civic education.

Education technology. Digital Culture.

\section{Schools and internet: spaces for civic education}

In face of the recent social crisis caused by the Covid-19 pandemic, it is an urgent task for the field to revisit the fundamentals of education in digital culture to enhance an emancipatory perspective of education today. Despite the promise of democratic expansion brought by the internet and other digital information and communication technologies, what we are seeing is a reconfiguration of the cultural industry due to the proliferation of hate speech, fake news, digital political marketing, data capitalism, and other forms of violence on digital networks. The task of research in education at the moment is to reflect and enunciate the challenges posed by the integration of technologies in everyday life while looking for spaces of possibility for the existence and critical formation of citizens in the context of digital culture. The article elaborates a theoretical reflection to consolidate the bases of another educational paradigm based on human rights education in a school connected with the world. From a critical perspective, it proposes that education deals with the critical reading of the media, but also with experimenting with forms of creative appropriation that educate subjects as authors and producers of their history.

\section{Resumen}

Palabras clave:

Educación

ciudadana.

Educación y tecnología. Cultura

Digital.

\section{Escuela e internet: espacios de educación ciudadana}

Frente a la reciente crisis social causada por la pandemia Covid-19, es una tarea urgente para el campo revisar los fundamentos de la educación en la cultura digital para mejorar una perspectiva emancipadora de la educación actual. A pesar de la promesa de expansión democrática que aportan Internet y otras tecnologías de la información y la comunicación digitales, lo que estamos viendo es una reconfiguración de la industria cultural debido a la proliferación del discurso de odio, las fake news, el marketing político digital, el capitalismo de datos y otras formas de violencia en las redes digitales. La tarea de la investigación en educación en este momento es reflexionar y enunciar los desafíos que plantea la integración de las tecnologías en la vida cotidiana buscando espacios de posibilidad para la existencia y formación crítica de la ciudadanía en el contexto de la cultura digital. El artículo elabora una reflexión teórica para consolidar las bases de otro paradigma educativo basado en la educación en derechos humanos en una escuela conectada con el mundo. Desde una perspectiva crítica, propone que la educación se ocupa de la lectura crítica de los medios, pero también de experimentar con formas de apropiación creativa que configuran a los sujetos como autores y productores de su historia. 


\section{Introdução}

A sociedade brasileira começou o ano de $2021 \mathrm{em}$ uma profunda crise. Uma pandemia causada pela Covid-19, que não só demonstrou a fragilidade da democracia em nosso país como escancarou problemas históricos ainda não resolvidos. A relação entre tecnologia e sociedade é um caso exemplar que ilustra a questão. Na medida em que, como medida de segurança sanitária, escolas e locais de trabalho foram fechados, exigindo que a comunicação, na educação e no trabalho, repentinamente dependesse do uso de tecnologias digitais, vimos temas antigos sendo trazidos à pauta e buscando a aceleração de decisões por muitos anos embargadas.

Por esse motivo, torna-se urgente revisitar fundamentos da educação na cultura digital, para reforçar e potencializar a possibilidade de uma abordagem crítica e criativa em uma perspectiva democrática e emancipadora. Diante da promessa de ampliação democrática que a criação da internet permitiu, inclusive com a revitalização do civismo nos movimentos sociais, articulados tanto nas redes sociais como na rua, até o cenário consolidado de difusão de fake news, a customização do marketing político digital, o capitalismo de dados, a proliferação de discurso de ódio e outras violências nas redes digitais, precisamos colocar em balanço a existência e a formação de cidadãos na cultura digital. É tarefa urgente da pesquisa em educação refletir sobre o seu papel e o lugar da escola na criação de alternativas que sejam emancipadoras nesse contexto. Descrever e enunciar o que está acontecendo, buscando ressignificar as teorias que nos orientam a partir de uma perspectiva crítica, pode vir a identificar espaços de oportunidade para a formação crítica de sujeitos na escola conectada com o mundo. Este é o objetivo principal deste artigo.

O cenário atual não é animador. Na maioria dos indicadores de desenvolvimento humano, como o acesso à educação e saúde, o Brasil ocupa posições intermediárias. A exceção de nossa presença nos extremos dos rankings se dá em um único dado: a desigualdade de renda. "Este indicador destoa dos demais números e torna o Brasil irreconhecível entre seus parceiros de PIB [Produto Interno Bruto] e população. É anômalo" (MENDONÇA, 2008, p. 230). Em desigualdade de renda, ocupamos as piores posições no mundo, figurando tradicionalmente entre as dez últimas. A pandemia de Covid-19 agrava esse cenário: no Brasil, o ano de 2021 começou com mais miseráveis que há uma década, de acordo com pesquisas da Fundação Getúlio Vargas (FGV), a partir de dados das Pesquisas Nacionais por Amostra de Domicílios (Pnad).

Essa conjuntura revela um cenário de crise do ideal democrático, descrito por Boaventura Santos (2016) como de equilíbrio entre liberdade e justiça social. Para o autor, a democracia é precisamente o processo de transformação de relações desiguais de poder em relações partilhadas de autoridade. Sendo assim, questiona: "Há futuro para a democracia num mundo dominado pelo capitalismo financeiro global, 
pelo colonialismo e pelo patriarcado nas relações sociais?” (SANTOS, 2016, p. 203). Em sua compreensão, vivemos em sociedades politicamente democráticas e socialmente fascistas.

Mais dados, anteriores à pandemia de Covid-19, corroboram essa percepção. Segundo relatório da organização internacional Oxfam, que anualmente publica dados sobre desigualdade no País, a proporção de renda da população negra em relação à da população branca está estagnada desde 2011, e em 2018 testemunhamos o primeiro recuo na equiparação de renda das mulheres (PAÍS..., 2018).

Diante desse cenário, como falar do exercício do direito à criação e ao desenvolvimento de um projeto de vida, tal como reconhecido pela Corte Interamericana de Direitos Humanos? A jurisprudência assegura a cada um a autonomia para realizar escolhas sobre quais caminhos irá seguir para se realizar existencialmente.

O direito em questão expressa que todo indivíduo, em sua condição de sujeito de direitos, deve usufruir dos pressupostos necessários para desenvolver sua personalidade, fazer suas escolhas de acordo com seus valores e objetivos, participar das deliberações públicas e de ações econômicas, sociais e políticas. (HACHEM; BONAT, 2017, p. 83).

Ou seja, o direito ao projeto de vida versa sobre o que Amartya Sen (2000) chama de condição de agente, que se refere à possibilidade de as pessoas escolherem e criarem condições para viverem uma vida que lhes faça sentido. Tal perspectiva se relaciona diretamente com a defesa de Santos (2016) sobre a necessidade de transformação de relações desiguais de poder em relações partilhadas de autoridade.

Esse entendimento de democracia, que extrapola a mera criação de normas e procedimentos de legitimação de ocupação do poder (BOBBIO; MATTEUCCI; PASQUINO, 2010), conclama a formação de sujeitos desejosos e aptos a entender e criticar sistemas de poder e injustiça - definição de Gee (2000) para pensamento crítico. Assim, enxergamos um vínculo indelével entre os desafios ora apresentados e a educação, tanto na sua dimensão de universalização do acesso quanto em qualidade de formação crítica. Tratamos aqui de determinada concepção de educação, que almeja a emancipação social e reivindica um papel ativo do Estado. Dessa forma, a educação, em especial a pública, torna-se um espaço privilegiado para tratar as desigualdades sociais e promover a igualdade de oportunidades.

Não é à toa que o direito à educação, tal qual preconizado na Constituição Federal do Brasil, não trata apenas da capacitação para o mercado de trabalho. Os termos da lei são claros e bem mais abrangentes, explicitamente afirmam que visam “[...] ao pleno desenvolvimento da pessoa, seu preparo para o exercício da cidadania e sua qualificação para o trabalho" (BRASIL, 1988, art. 205). O que significa que, enquanto se capacita para o trabalho, cada pessoa tem o direito de ter a formação e os instrumentos para escolher seus próprios projetos de vida, sendo a educação básica obrigatória um espaço decisivo na garantia ou não desse e de outros direitos humanos, tendo em vista já haver consenso sobre o fato de a educação ser um caminho de prevenção das violações de direitos humanos. 
Trata-se de reconhecer a educação como espaço de empoderamento dos sujeitos por meio de uma formação para a cidadania comprometida, ativa e engajada com o contexto da vida cotidiana desses sujeitos. Empoderamento entendido em sua dupla dimensão, individual e social, de modo a ser direcionado, sempre, para a redução da assimetria no poder (FORTUNATI, 2014).

Porém, pensar a educação na conjuntura atual demanda a consideração do contexto vivenciado, permeado pela cultura engendrada a partir do uso das tecnologias de informação e comunicação (TIC), a cultura digital. Se já em meados do século passado a crítica da Escola de Frankfurt nos apontou as estratégias de manipulação e controle social pela comunicação mediada por tecnologias, hoje podemos observar, com a penetrabilidade das TICs em todos os âmbitos da vida (econômica, social, cultural, política, etc.), uma reconfiguração da indústria cultural na reprodução de homens de uma única dimensão e um acirramento da adesão voluntária das pessoas às estratégias de dominação que se infiltram por meios digitais, cada vez mais disseminados em sociedade.

Portanto, falar em educação para a cidadania no contexto da cultura digital nos remete a uma premente reflexão anterior, sobre as tensões que as TICs vêm impondo à democracia, aos sujeitos e às escolas. Conhecer as determinações postas pelas tecnologias e fazer uma leitura crítica do mundo tal qual ele se apresenta é condição primeira para projetarmos um mundo melhor. Pois, ainda que a comunicação pelos meios digitais se configure uma nova modalidade da indústria cultural 2.0 (DUARTE, 2011), a perspectiva crítica vai buscar a brecha, a possibilidade de subversão da lógica programada (MACHADO, 2007), por meio da apropriação crítica dos meios (LAPA, 2013). Apropriação esta que requer não apenas um uso consciente e crítico, mas também uma produção criativa e autoral com para e através das mídias na cultura digital.

\section{Democracia e internet}

\section{A Promessa}

Como lembra Pretto (2017), a criação da internet aconteceu de forma compartilhada e socializada em rede. Surgiu como um rossio (SIMON; VIEIRA, 2008): um espaço público que possibilita a troca entre as pessoas. Nas palavras de Berners-Lee (2017), o criador do protocolo que foi fundamental para a popularização da internet, o world wide web $(W W W)$ : a internet é “[...] uma plataforma aberta, que permite que qualquer um compartilhe informações, acesse oportunidades e se engaje na colaboração independentemente de barreiras geográficas" (tradução nossa). ${ }^{1}$ Desse comportamento deriva o fortalecimento da ideia da rede como um lugar de criação de comunidades.

No início, blogs e outras formas de comunicação on-line ganharam adesão: salas de bate-papo, mensageiros instantâneos, serviços de conexão por voz, jogos e sites de publicação de fotografias (que no início permitiam o upload de apenas uma imagem por dia). Todo esse contexto comunicativo propiciou a 
emergência da netculture - cultura da rede, em tradução literal. Ou seja, a troca comunicativa nesses espaços fez surgir um código comum aos usuários dessas tecnologias, resultado da formação de comunidades, dos espaços de reflexão compartilhada e da emergência de uma cultura colaborativa (MALINI, 2007).

Interessa-nos especialmente, nesta recapitulação da emergência da netculture, o papel participativo que se vislumbrava para os sujeitos nesse momento. A percepção da internet como um espaço de possibilidade de contestação de estruturas já constituídas de poder (seja ele político, econômico ou midiático) começa em 1999, com a cobertura independente que se deu na rede aos protestos realizados durante a reunião da Organização Mundial do Comércio (OMC) na cidade de Seattle (Estados Unidos). Ela deu origem a uma rede mundial de jornalismo independente, a Indymedia, que três anos depois já contava com 89 sites, distribuídos em 31 países (ESPIRITUSANTO;. GONZALO, 2011).

Em 2007, uma outra onda de protestos, desta vez a Revolta do Açafrão, na Birmânia (Saffron Revolution), fez da rede uma ferramenta estratégica para os manifestantes, por meio da difusão das imagens de violência do Estado durante a repressão dos protestos. Ao estudar essas manifestações, o pesquisador Mridul Chowdhury (2008) conclui que mesmo regimes autoritários temem a opinião pública e que a possibilidade de uma autocomunicação de massa pela internet (CASTELLS, 2013), possivelmente, salvou a vida de milhares de pessoas.

O fenômeno da apropriação popular do espaço midiático trazia tensionamentos não apenas à manifestação política do poder. Sua influência se dava também sobre a indústria da cultura. Ao longo de toda a primeira década dos anos 2000, as práticas colaborativas e de compartilhamento de arquivos na internet impuseram uma revisão de modelo de negócio à indústria do entretenimento, que culminou com o aparecimento de serviços de vídeo e música por streaming. A relação com a indústria da cultura também foi desestabilizada em razão das possibilidades de criação do público, que se ampliaram com a chance de trabalho colaborativo; de disseminação e diálogo direto com o público; e de interação com obras da cultura comercial, a partir de cópias e releituras (JENKINS, 2009).

Esses e muitos outros exemplos foram percebidos como sinais incontestes de que uma alteração fundamental estava acontecendo no campo da comunicação, com desdobramentos em toda a sociedade. A internet se apresentava como uma alternativa de descentralização da influência dos veículos massivos, de governos e empresas. Em meio a toda discussão sobre as alterações que as TICs traziam à sociedade, havia motivos indiscutíveis para o otimismo em relação às possibilidades de contestação das estruturas hegemônicas, principalmente em razão do aproveitamento da autonomia comunicativa criada com a rede (CASTELLS, 2013) para a organização de mobilizações políticas.

Teóricos de renome apontavam os elementos que poderiam dar ensejo a uma radical transformação social a partir das práticas que se consolidavam em rede. Benkler (2006) escrevia que, à medida que a 
população passasse a integrar e a interferir na agenda midiática, a forma com que as posições sociais são cristalizadas seria alterada. Shirky (2011) demonstrava o potencial criativo da cultura da participação. E Jenkins (2009) chamava a atenção para a colisão entre uma cultura de mídia emergente, com mais protagonismo do público.

\section{O cenário consolidado}

Não sugerimos aqui que o otimismo em relação às possibilidades de transformação social a partir do uso da rede não tinha fundamento. Muito pelo contrário. São fartos os exemplos de como a internet foi importante para articular mudanças sociais também ao longo desta segunda década dos anos 2000. Buscamos demonstrar um pouco da construção da compreensão da internet como um lugar de possível revisão de práticas, que poderia ampliar as possibilidades de emancipação social. Percebemos, no entanto, que muitas implicações foram trazidas a este horizonte, conforme outros atores passaram a ter destaque na rede, como o mercado.

A Organização não Governamental sem fins lucrativos Mozilla, que atua na manutenção da internet como um recurso público global, aberto e acessível a todos, elenca cinco eixos principais de atenção em relação à internet: segurança; abertura; inclusão digital; educação para o uso das mídias; e controle (MOZILLA FOUNDATION, 2018).

Refletir sobre o potencial democrático da internet significa tratar da passagem tão esperada de consumidores a cidadãos (CANCLINI, 1999). Evidentemente, implica o acesso das pessoas à rede não apenas na dimensão de seu uso mas também na sua produção. Em relação ao primeiro aspecto, 28\% das residências brasileiras não têm conexão com a internet (CETIC, 2019). Sobre o segundo, o setor de aplicativos para telefones celulares se baseia apenas em países com altos índices econômicos (95\% do valor movimentado neste setor vêm de 10 países) (MOZILLA FOUNDATION, 2018), o que significa dizer que os demais apenas usam soluções que não foram criadas para a sua realidade. Além disso, 75\% dos desenvolvedores da internet são homens, de acordo com dados da ONU Mulheres. ${ }^{2}$

A presença de grandes empresas mediando a comunicação travada na internet, bem como as políticas de regulamentação da rede, ${ }^{3}$ inquieta aqueles que vislumbraram seu potencial transformador: " $O$ sistema está falhando. A maneira como a receita de publicidade funciona com conteúdos caça-clique não está realizando o objetivo de ajudar a humanidade a promover a verdade e a democracia. Por isso, eu estou preocupado" (BERNERS-LEE, 2017, grifos nossos).

O relatório Internet Monitor, produzido pelo Berkman Center for Internet and Society, da Universidade de Harvard (EUA), é categórico: “As empresas privadas controlam a grande maioria da infraestrutura física da Internet e grande parte do software que repousa sobre ele e, portanto, desempenham um papel profundamente influente na definição de espaços online” (GASSER et al., 2014, p. 31). 
É justamente nos espaços privados que os usuários passam o maior tempo de sua navegação. No Brasil, a média de tempo gasto nas redes sociais da internet é de 3 horas e 31 minutos por dia, de acordo com a pesquisa Global Digital Overview 2020 (KEMP, 2020). O País ocupa o terceiro lugar no ranking mundial, atrás da Colômbia ( 3 horas e 45 minutos) e das Filipinas (3 horas e 53 minutos), também de acordo com o estudo.

As principais redes sociais são de propriedade das empresas, que, atravessadas por sua finalidade de lucro, desenham a arquitetura desses softwares. Uma metáfora utilizada por intelectuais e ativistas para descrição do atual contexto da internet é de que ela foi concebida para ser uma praça e acabou se tornando um shopping center, já que é em ambientes privados, como um shopping, e não nos públicos, como uma praça, que acontece a maior parte do tráfego.

Como lembra Zuboff $(2015,2019)$, as empresas que hoje concentram a navegação na internet são sustentadas pelos dados coletados a partir das atividades dos cidadãos na rede, que, muitas vezes, não se dão conta de que não estão utilizando um serviço gratuito. Assim, vem se constituindo aquilo que Nick Srnicek (2018) denomina de Capitalismo de Plataforma.

Dessa forma, as redes sociais operam o que Pariser (2011) chamou de filtros-bolha: algoritmos que privilegiam determinados assuntos em detrimento de outros, a partir das preferências que os usuários demonstram por seus hábitos de interação on-line. Ao descrevê-las, o autor chamou a atenção para a tendência de eliminação de contato com o pensamento dissonante, ou diferente do próprio.

Em pesquisa anterior (COELHO, 2015), verificamos a existência da tendência apresentada por Pariser (2011) em nosso país. A partir de análises de conversações realizadas no Twitter durante os protestos por aumento de tarifas nas manifestações de 2013 a 2015 no Brasil, percebemos que: a) a reafirmação da própria perspectiva era muito mais recorrente que a disposição em compreender e estabelecer relação com ideias diferentes (quase $80 \%$ das mensagens estudadas); b) a presença relevante de mensagens de cunho agressivo, com posts que continham menosprezo, ironia, preconceito e incitação/apologia à violência (48\% da amostra) (COELHO, 2015).

Outro agravante é a propagação de conteúdos falsos, muitas vezes impulsionados por softwares que simulam usuários humanos (os chamados bots, diminutivo para robots, robôs em inglês), com a intenção de favorecer uma determinada agenda. O desafio na internet, mais do que falar, é ser ouvido (CASTELLS, 2013). Por isso, a batalha por atenção integra a criação de dinâmicas de diálogo na rede. Os bots, inclusive, participaram com destaque de acontecimentos políticos recentes no Brasil, como os protestos pelo impeachment da presidente da República Dilma Rousseff e as eleições presidenciais de 2014 (ARNAUDO, 2017) e 2018 (NOBRE; ALMEIDA; FERREIRA, 2019). 


\section{O papel da educação e da escola}

Até o momento, tratamos de apresentar o crescente quadro de desigualdade no Brasil e como a internet promoveu o seu acirramento, ao invés de contribuir para o seu enfrentamento. Apesar de ser um meio mais democrático, que nasceu por iniciativas colaborativas e propôs uma reorganização de poderes na comunicação e na sociedade, ali também se estenderam as práticas capitalistas, colonialistas e patriarcais que continuam a se impor no Brasil, impedindo o fortalecimento da democracia para estágios de mais alta intensidade. Nesse contexto, resgatamos a defesa da perspectiva crítica de um não determinismo tecnológico e da potencialidade latente nas formas de apropriação que os sujeitos são capazes de engendrar ao buscar subverter a lógica programada em busca de alternativas. Assim, reafirmamos o relevante papel da educação como espaço de empoderamento dos sujeitos em uma formação para a cidadania.

Mesmo concordando que, após o crescente acesso à informação e a toda sorte de conhecimentos socialmente produzidos pela internet, a educação para a cidadania, que, sabemos, pode acontecer em qualquer lugar, tem seu lugar privilegiado nas escolas, principalmente as públicas. Porque, apesar de a escola ser o lugar da socialização das crianças e dos jovens e da reprodução das estruturas de poder vigentes, ela também é o lugar de oportunizar a igualdade de acesso e de formação para o uso crítico e criativo das tecnologias, conhecimento essencial na cultura contemporânea, para que cada pessoa possa estabelecer seus próprios projetos de vida, buscando meios para realizá-los. Com isso afirmamos enfaticamente: a escola é o espaço controlado pelas forças vigentes exatamente porque tem o potencial de subvertê-las por meio de uma educação emancipadora dos sujeitos. A aposta está em como promover a formação de cidadãos capazes de pensar criticamente, de projetar futuros alternativos e de agir pela sua transformação. Para que essa possibilidade exista, precisamos garantir, tal qual alertado por Feenberg (2002), instituições apropriadas para exercer o controle humano sobre a tecnologia. Estamos falando da escola que integra as TICs com essa proposta crítica.

\section{TIC na escola: desafio e oportunidade}

Quando falamos de escola, o discurso comum é o da carência. Alguns fatos nos ajudam a compor o cenário, nada animador. Segundo dados do Centro Regional de Estudos para o Desenvolvimento da Sociedade da Informação (CETIC, 2020), em 2019,99\% das escolas localizadas em áreas urbanas possuíam ao menos um computador com acesso à Internet. Parece bom, mas, se detalhamos esses dados, percebemos seus limites. O perfil de uso dos recursos pelos alunos demonstra diferenças: enquanto nas escolas particulares $82 \%$ acessam a internet na sala de aula, nas públicas o percentual é de $63 \%$.

A conectividade à internet é um fator que deflagra desigualdades: enquanto a conexão superior ou igual a $11 \mathrm{Mbps}$ é realidade em $52 \%$ das escolas particulares, apenas $27 \%$ das públicas usufruem dessa 
velocidade de acesso. Além disso, os alunos que responderam à pesquisa afirmaram que não têm autorização para utilizar o wi-fi da escola (52\% nas escolas públicas e 46\% nas particulares).

Essa realidade esclarece, em grande parte, a frequente queixa de professores sobre a falta de condições adequadas no sistema público de ensino. Contudo, vale a pena fazer uma ressalva sobre a uniformização desta leitura generalista da escola pública, pois há distorções que são esclarecidas pelos distintos contextos de financiamento (municipal, estadual e federal). Tal fato ficou evidente quando os Institutos Federais foram corretamente reincluídos nas estatísticas divulgadas acerca da qualidade da escola pública nas notas do Enem 2018 e do Pisa 2015. Ao subirem os índices drasticamente, ficou demonstrado que a escola pública, quando tem recursos e condições a oferecer a seus professores, consegue garantir um ensino de qualidade (BORGES, 2016).

Feita a ressalva quanto às condições estruturais que limitam as ações na escola, vamos focar no desafio, que não é pequeno, da integração de TICs na educação. Isto é, quando as TICs estão presentes na escola, ainda assim a sua integração geralmente assume uma perspectiva instrumental.

\section{As práticas que são realizadas com as TICs}

Em um contexto de aulas presenciais, anterior à pandemia de Covid-19, a pesquisa TIC Educação (CETIC, 2019) mostra que as principais atividades desenvolvidas pelos professores com TICs foram: disponibilizar conteúdos para os alunos (44\%), tirar dúvidas pela internet (36\%) e utilizar programas educativos de computador (23\%). As atividades de criação a partir da interação com a rede foram mais raras: apenas $11 \%$ desenvolveram projetos com os alunos, $3 \%$ criaram sites, páginas ou blogs e $1 \%$ criou jogo de computador ou aplicativo.

$\mathrm{Na}$ sala de aula, o uso de internet em atividades pedagógicas se faz, em sua maioria, por meio do acesso privado. $\mathrm{O}$ acesso à internet na escola é restrito, e nem todos os sites e plataformas da rede são acessíveis aos alunos. Além disso, talvez justamente por isso, 49\% usaram o 3G/4G do próprio celular para atividades, contra $27 \%$ que usaram o wi-fi da escola.

Fica evidente, pelos dados, que é insignificante o uso de TICs na produção coletiva de conhecimento na escola e que a maioria dos professores ainda adota a tecnologia como ferramenta para fazer uma exposição mais performática dos conteúdos. Quer dizer, a inovação na escola está reduzida à presença de tecnologias na mesma pedagogia tradicional, geralmente transmissiva e bancária, seja devido à restrição de infraestrutura (internet de banda larga liberada para os estudantes, por exemplo), seja devido à formação de professores, focada na capacitação instrumental dos recursos (LAPA; PRETTO, 2019).

Contudo, fora da escola, as crianças e jovens têm usado a internet e outros recursos tecnológicos como fundamento da cultura contemporânea. Como próteses, os gadgets fazem parte da vida cotidiana 
desses jovens, como contexto cultural, como fundamento que conforma outras formas de pensar, de conhecer, de se relacionar (com os outros e com o mundo).

Durante a pandemia de Covid-19, em que as TIC se tornaram condição para a continuação do trabalho pedagógico, a pesquisa Undime sobre Volta às Aulas 2021, realizada pela União Nacional dos Dirigentes Municipais de Educação (UNDIME, 2021) em escolas municipais de 67\% dos municípios do País, mostra que:

- $1,9 \%$ das escolas trabalharam no ano de 2020 apenas com atividades não presenciais;

- Das estratégias de atividades pedagógicas não presenciais adotadas, o material impresso foi o principal recurso $(95,3 \%)$, seguido de orientações enviadas por meio do aplicativo WhatsApp $(92,9 \%)$. Em seguida, aparecem as aulas gravadas (61,3\%), as orientações enviadas por outros aplicativos (54\%); o uso de plataformas educacionais (22\%); as aulas síncronas em vídeo (21,3\%), as aulas pela TV $(4,1 \%)$; e as aulas pelo rádio $(2,6 \%)$.

A pesquisa revelou ainda que os aplicativos e plataformas mais especializados podem ser uma realidade em municípios maiores, mas não são dominantes. A participação dos alunos foi inferior a $75 \%$ em mais de metade dos municípios respondentes (60\%).

De acordo com outro estudo, realizado pela Fundação Carlos Chagas (FCC) e a Organização das Nações Unidas para a Educação, a Ciência e a Cultura (Unesco) ainda nos primeiros meses de pandemia (maio de 2020), as principais estratégias para continuidade das atividades de ensino foram: envio de materiais digitais via redes digitais $(77,4 \%)$; envio de orientações às famílias $(54,2 \%)$; publicação de materiais nos sites das Secretarias de Educação (47,5\%) e de videoaulas gravadas (38,3\%); envio de atividades impressas aos alunos (37,2\%); e realização de aulas ao vivo (29,8\%). Ou seja, a maior parte das práticas são aquelas conduzidas com materiais estáticos, que não possibilitam a interação entre a turma e os professores (FCC; UNESCO, 2020).

A situação apresentada acima descreve e atualiza o descompasso da escola com a cultura digital, que aparta os processos atuais de mediação social de construção de conhecimento das escolas e do espaço público contemporâneo (MARTÍN-BARBERO, 2005, 2014; ORÓZCO-GOMEZ, 2007; BUCKINGHAM, 2007).

E, com ele, vimos renascer o discurso da obsolescência da escola, inspirado na defesa da desescolarização de Illich (1971), como se, por meio do acesso livre e ilimitado à informação disponível nas redes digitais de comunicação, um sujeito autônomo pudesse aprender sozinho, isto é, como se a internet, agora, pudesse ser a sua escola. Acreditamos que essa é uma visão equivocada, pois podemos adotar a compreensão de que passamos de uma sociedade com sistema de ensino para uma sociedade educacional (MARTÍN-BARBERO, 2014) ou de que a internet pode ser um espaço público educativo 
(NÓVOA, 2015), do qual diversos espaços formativos sociais e culturais emergem, sob a responsabilidade de várias instituições. Mesmo reconhecendo o potencial educativo de práticas realizadas na internet, não podemos negligenciar o papel da escola como o espaço primordial da educação para a cidadania, por ser o espaço da convivência social e da construção coletiva de sentidos, que transcende, e muito, a simples 'aquisição' individual de conteúdos.

O perigo aí está justamente na tendência a desqualificar a escola, e não de transformá-la. Como já dizia Freire (1987), a educação não tem sido uma alavanca para a transformação da sociedade justamente porque ela poderia ser. Portanto, o enfraquecimento da escola pública não é por falta de um projeto para a educação, mas por haver um projeto claro, que, sob a aparência de neutralidade, é, no fundo, neoliberal em suas práticas, o que consolida e amplia as desigualdades sociais por meio do controle sobre a potência de nascimento das oportunidades de transformação, isto é, a formação crítica de cidadãos.

Assertivamente, Martín-Barbero (2005, p. 67) descreve esta problemática:

\begin{abstract}
Os meios de comunicação e as tecnologias de informação significam para a escola sobretudo um desafio cultural, que deixa visível a brecha cada dia maior entre a cultura a partir da qual os professores ensinam e os alunos aprendem. Pois os meios de comunicação não somente descentralizam as formas de transmissão e circulação do saber, mas constituem um âmbito decisivo de socialização, de dispositivos de identificação/projeção de pautas de comportamento, de estilos de vida e padrões de gosto. (grifo do autor).
\end{abstract}

Entendendo a importância da educação para a cidadania como um lugar privilegiado para que uma mudança ocorra, voltamos nosso olhar para a escola com TICs em busca de alternativas. E observamos que a educação e a escola não acontecem, assim, no singular. Trata-se de educações, como falam Pretto e Pinto (2006), e de escolas, que, apesar de todas as restrições e dos perigos apontados anteriormente, acontecem em uma multiplicidade de formatos e experiências, construídas cotidianamente por pessoas diferentes, que conformam as escolas como espaços multifacetados de diversas iniciativas que fogem do padrão. São espaços de oportunidades. Eles são criados na escola, cotidianamente, a despeito de toda a pré-disposição em contrário.

\title{
A escola conectada com o mundo: o lugar do sujeito
}

A pergunta-chave, então, reside em como poderia ser esta escola da cultura digital. Retomando Paulo Freire (1987, 1989), buscamos a sua ênfase na consideração do contexto em todo processo educativo, em especial quando ele diz: “A educação autêntica, repitamos, não se faz de A para B ou de A sobre B, mas de A com B, mediatizados pelo mundo" (FREIRE, 1987, p. 97). De modo que uma educação escolar que se pretenda hoje descolada ou isenta do que acontece na cultura digital, mesmo que sob o argumento da proteção de crianças e jovens contra a exposição midiática, é só mais um pretexto para realizar uma educação descontextualizada e, portanto, restritiva das condições de formação crítica de cidadãos. 
Vinte e cinco anos depois da internet comercial, a rede não pode mais ser compreendida como uma novidade ou um fator novo, como acontecia em boa parte dos estudos sobre comunicação e sociedade nas décadas de 1990 ou 2000, que tratavam a internet como uma entidade à parte da cultura, deslocada em uma cultura própria (FRAGOSO; RECUERO; AMARAL, 2012). O atual contexto social é permeado pelas dinâmicas das comunicações digitais, que fazem do espaço público um espaço híbrido, resultante da interação entre as práticas presenciais e digitais (CASTELLS, 2013), ou seja: “[...] o mundo agora já não é algo sobre o que se fala com falsas palavras, mas o mediatizador dos sujeitos da educação, a incidência da ação transformadora dos homens, de que resulte a sua humanização" (FREIRE, 1987, p. 75)

O ponto de partida é justamente a relação homem-mundo, "[...] no seu aqui e no seu agora que constituem a situação em que se encontram ora imersos, ora emersos, ora insertados" (FREIRE, 1987, p. 74). Posto que não é o corpo (ou seu avatar, como Gibson primeiramente enunciou em 1984) que navega em diferentes espaços: atual e ficcional; material e imaterial; dentro da escola e fora, na internet. Esta concepção é a mesma que muitas vezes denunciou a fragmentação da personalidade dos indivíduos, agora dividida em seus diversos perfis e aplicativos.

De fato, defendemos que o que navega são os diferentes espaços que adentram o corpo do sujeito e nele são significados. Todos os perfis, todos os espaços virtuais e materiais habitam o mesmo corpo, com suas inconsistências e contradições. Sendo assim, o sujeito é o lugar de confluência dos espaços de aprendizagem on-line e off-line, dentro e fora da escola. É no sujeito que as aprendizagens se tornam corpo. Todas elas, as que acontecem dentro e fora dos muros da escola, sob um aparente controle desta, mas também sob a aparente liberdade da internet. As experiências de aprendizagem dos sujeitos conformam sua existência no mundo, que é um híbrido online e off-line.

Por essa razão, os profissionais da educação na escola, sabedores desta potência que é a possibilidade de formação de sujeitos críticos para a ação política transformadora e emancipadora no mundo, de fato, têm uma responsabilidade enorme ao promover ou não esta oportunidade pela maneira como integram as TICs às suas práticas pedagógicas. É certo que não conseguirão criar alternativas se reduzirem a presença de tecnologias na escola a instrumentos de uma pedagogia anterior à difusão da internet, a simples meios para melhorar a exposição de conteúdos ou ainda a componente curricular específico. Se não alcançarem uma integração que promova a autonomia, a criação e a produção de conhecimentos e sentidos coletivamente, com e através dos meios da cultura digital, não estarão, ainda, promovendo uma formação crítica para a cidadania no contexto da cultura digital.

O fator determinante para que a escola possa ser o lugar da educação que promove o empoderamento e a formação para a cidadania é a compreensão do aluno como sujeito, que é, como vimos tratando, o indivíduo capaz de dar sentido às suas vivências, elaborar conceitos, ideias e teorias (LAPA et al., 2018). Um sujeito que faz a leitura crítica do mundo em que vive e que busca alternativas para transformar o 
mundo naquilo que gostaria que fosse. Além dessas duas etapas reflexivas, há as da ação: encontrar os meios para efetivar a mudança e escolher agir. Porque é no projetar um mundo melhor e buscar, na práxis, a sua realização que podem ser concluídas as quatro etapas da busca da liberdade. Vale ainda ressaltar que o mundo de que estamos tratando já é, inevitavelmente, atravessado pelas TICs, e é com e através delas que as pessoas expressam e produzem cultura. Portanto, a formação crítica de sujeitos para a ação política no mundo não pode prescindir de passar por todas estas etapas da busca da liberdade bem assentadas na cultura digital, com a apropriação crítica e criativa das TICs que propusemos antes.

Nessa perspectiva, a educação desejada é a que faz com que alunos possam ser autores, os sujeitos da práxis, com uma conduta participativa e modificadora de sua comunidade, conscientes do mundo em que vivem, para agir no sentido de transformá-lo e de criar um contraponto ao discurso hegemônico.

Exatamente por isso, sugerimos aqui uma outra apropriação da internet: que supere a mera reprodução do conteúdo programático e estabeleça um canal de conhecimento, significação e apropriação da realidade, com vistas à criação dos alunos. E sugerimos a explosão do conceito de escola limitada e contida do senso comum, pois as escolas, segundo a perspectiva que desenvolvemos até agora, seriam ainda mais imprescindíveis. O que defendemos é que poderiam ser pensadas como centros de cultura, como os espaços de produção de conhecimento que são, em sua interrelação com o mundo, imersas, e não como complemento do mundo exterior e da cultura digital, porque ali os muros são membranas permeáveis ao mundo e suas diversas formas e contextos de aprendizagens.

\section{Considerações finais}

Buscamos desenvolver, em nosso trabalho, a inclusão da temática da cultura digital em reflexões sobre uma concepção de educação comprometida com a formação de sujeitos aptos e desejosos de agir sobre a estrutura social, de forma a reivindicar direitos para aqueles que se encontram cada vez mais alijados de humanidade na conjuntura atual. Uma educação, conforme prescreve Freire (1987, p. 91), como prática de liberdade:

Acho fundamental que, compreendendo a história como possibilidade, o educador descubra a educação também como possibilidade, na medida em que a educação é profundamente histórica [...] mesmo reconhecendo que a educação no outro século não vai ser a chave da transformação do concreto para a recriação, a retomada da liberdade, mesmo que saibam que não é isso, estejam convencidos da eficácia da prática educativa como elemento fundamental no processo de resgate da liberdade.

Verificamos que, embora a internet tenha sido criada sob aspirações de ampliação da democracia e tenha-se vislumbrado nela um ambiente sobre o qual a emancipação social poderia ser construída, este espaço é hoje atravessado por múltiplas contradições. Embora seja um importante lugar de articulação de movimentos sociais, é também desenvolvida a partir de estruturas que visam à comercialização de produtos, 
em que o fluxo de comunicação é atravessado por conteúdo falso, ou artificialmente manipulado para defender ideias de cunho político.

Por isso, entendemos que é fundamental ao campo da educação abordar a cultura digital de forma crítica e criativa, pois é também nela que se desenvolve o presente. Não é, dessa forma, no entanto, que verificamos que as TICs vêm sendo incorporadas ao cotidiano das escolas, conforme demonstram os dados da pesquisa TIC Educação citados neste trabalho. Tal como foi descrito, o recurso às TICs se dá, principalmente, como atualização performática da mesma pedagogia tradicional e ultrapassada.

Por isso, nossa proposta visa tornar a escola um lugar para a reflexão sobre a lógica programada e programadora dos artefatos técnicos que participam da nossa vida, e, simultaneamente, para a ação autoral, protagonista e transformadora, para o mundo e com o mundo, com e por meio das TICs. Entendemos, tal como defende Feenberg (2002), que se o significado de ser humano é decidido pelas nossas ferramentas, a retomada do civismo para o desenvolvimento tecnológico é condição sine qua non para que ele seja orientado a valores democráticos. Para isso, o conhecimento sobre os softwares e hardwares que utilizamos precisa ser profano, ou seja, dessacralizado, acessível, manipulável - da forma com que Masschelein e Simons (2017) defendem que deve ser o conhecimento. Não conseguimos pensar em lugar melhor para isso que a escola.

Da mesma forma, entendemos que nos cabe refletir e dar espaço em aula para os aprendizados que os alunos constroem nos espaços sociais virtuais. Mediar o repertório que eles constroem na rede a partir de uma ética republicana e democrática, em que são centrais, como estabelece Benevides (2007), o respeito às leis legitimamente elaboradas, a prioridade do bem público perante os interesses pessoais ou de grupos específicos, a responsabilidade de nossos atos como cidadãos, os valores da igualdade, liberdade e solidariedade.

Para nós, a possibilidade de existência de sujeitos reside na consciência crítica das condições postas em um contexto que é de dominação, assim como na busca de alternativas a ele, uma vez que o mundo apresenta determinações, mas não está, nunca, já determinado. Dessa forma, entendemos ser necessário olhar para as TICs como espaços de possibilidade para a transformação do mundo, tanto pela compreensão crítica como pela reinvenção do presente, o que vai muito além de entendê-las como recursos pedagógicos. 
Notas

1 "[...] an open platform that allows anyone to share information, access opportunities and collaborate across geographical boundaries".

2 Cf.: https://bit.ly/3AWoL6e. Acesso em: 7 abr. 2021.

3 Nesta entrevista, Berners-Lee se referia à intenção do governo do presidente estadunidense Donald Trump em aprovar uma lei que suspendia a garantia da neutralidade da rede no país - princípio que determina o tráfego não diferenciado de todos os pacotes de informação na internet, independentemente de quem é seu emissor. Significa, na prática, que ninguém pode pagar mais para ter seu conteúdo distribuído com mais prioridade, em detrimento de outros, o que é considerado central para a igualdade na rede.

4 Programa Internacional de Avaliação de Estudantes (Pisa), da Organização para Cooperação e Desenvolvimento Econômico (OCDE), em que o Brasil ficou em $63^{\circ}$ lugar entre 72 países.

\section{Referências}

ARNAUDO, Dan. Computational propaganda in Brazil: Social bots during elections. [Oxford]: University of Oxford, 2017. (Computational Propaganda Research Project, Working Paper, n. 2017.8). Disponível em: https://bit.ly/2XHyChV. Acesso em: 20 mar. 2020.

BENEVIDES, Maria Victoria. Educação em Direitos Humanos: do que se trata? BRASIL. Ministério da Educação. Programa Ética e Cidadania. [Brasília: MEC], 2007. p. 1-8. Disponível em: https://bit.ly/3mee8aI. Acesso em: 7 abr. 2021.

BERNERS-LEE, Tim. Tim Berners-Lee on the future of the web: 'The system is failing'. The Guardian, [S. l.], 16 nov. 2017. Entrevista. Disponível em: https://bit.ly/3sEh5T5. Acesso em: 7 abr. 2021.

BOBBIO, Norberto; MATTEUCCI, Nicola; PASQUINO, Gianfranco. Dicionário de Política. Brasília: Editora Universidade de Brasília, 2010.

BORGES, Helena. Estudantes federais têm desempenho coreano em ciências, mas MEC ignora. The Intercept Brasil, [S. l.], 8 dez. 2016. Disponível em: https://bit.ly/2UwmTRY. Acesso em: 7 abr. 2021.

BRASIL [Constituição (1998)]. Constituição Federal da República Federativa do Brasil. São Paulo: Revista dos Tribunais, 1988.

BUCKINGHAM, David. Crescer na era das mídias eletrônicas. São Paulo: Edições Loyola, 2007.

CANCLINI, Néstor García. Consumidores e cidadãos: conflitos multiculturais da globalização, Rio de Janeiro: Editora UFRJ, 1999.

CASTELLS, Manuel. Redes de indignação e esperança. Rio de Janeiro: Zahar, 2013.

CENTRO REGIONAL DE ESTUDOS PARA O DESENVOLVIMENTO DA SOCIEDADE DA INFORMAÇÃO (Cetic.br). TIC EDUCAÇÃO: Pesquisa Sobre o Uso das Tecnologias de Informação e Comunicação nas Escolas Brasileiras - 2018. São Paulo: Comitê Gestor da Internet, 2019. Disponível em: https://bit.ly/381CRGZ. Acesso em: 20 mar. 2021.

CENTRO REGIONAL DE ESTUDOS PARA O DESENVOLVIMENTO DA SOCIEDADE DA INFORMAÇÃO (Cetic.br). TIC EDUCAÇÃ̃o: Pesquisa Sobre o Uso das Tecnologias de Informação e Comunicação nas Escolas Brasileiras - 2019. São Paulo: Comitê Gestor da Internet, nov. 2020. Disponível em: https://bit.ly/381CRGZ. Acesso em: 20 mar. 2021.

CHOWDHURY, Mridul. The role of the internet in Burma's saffron revolution. Cambridge: The Berkman Center for Internet and Society at Harvard University, 2008. (Berkman Center Research Publication, n. 2008-08). Disponível em: https://bit.ly/3AUUVPl. Acesso em: 20 mar. 2020. 
COELHO, Isabel Colucci. Internet e Educação: aproximações inspiradas pelos movimentos sociais articulados em rede para a formação de sujeitos. 2015. 188 f. Dissertação (Mestrado em Educação) - Universidade Federal de Santa Catarina, Florianópolis, 2015.

DUARTE, Rodrigo. Indústria Cultural 2.0. Constelaciones: Revista de Teoría Crítica, [S. l.], n. 3, p. 90-117, 2011. Disponível em: http://bit.ly/2DvwHBB. Acesso em: 7 de abril de 2021.

ESPIRITUSANTO, Óscar; GONZALO, Paula (coord.). Periodismo ciudadano: evolución positiva de la comunicación. Barcelona: Ariel, 2011.

FEENBERG, Andrew. Transforming technology: a critical theory revisited. New York: Oxford University Press, 2002.

FORTUNATI, Leopoldina. Media Between Power and Empowerment: Can we resolve the dilemma? The Information Society, [S.l.], n. 30, p. 169-183, 2014. DOI: 10.1080/01972243.2014.896676. Disponível em: https://bit.ly/3sxxoB8. Acesso em: 20 mar. 2020.

FRAGOSO, Suely; RECUERO, Raquel; AMARAL, Adriana. Métodos de pesquisa para internet. Porto Alegre: Sulina, 2012.

FREIRE, Paulo. Ação cultural como prática da liberdade. Rio de Janeiro: Paz e Terra, 1976.

FREIRE, Paulo. Pedagogia do Oprimido. 17. ed. Rio de Janeiro: Paz e Terra, 1987.

FUNDAÇÃO CARLOS CHAGAS; ORGANIZAÇÃO DAS NAÇÕES UNIDAS PARA A EDUCAÇÃO, A CIÊNCIA E A CULTURA. Departamento de Pesquisas Educacionais. Pesquisa: Educação escolar em tempos de pandemia na visão de professoras/es da Educação Básica. FCC, São Paulo, 2020. (Informe nº 1). Disponível em: https://bit.ly/2UzifTf. Acesso em: 20 mar. 2021.

GASSER, Urs; ZITTRAIN, Jonathan L.; FARIS, Robert; JONES, Rebekah. Internet Monitor 2014: Reflections on the Digital World: Platforms, Policy, Privacy, and Public Discourse. Cambridge: The Berkman Center for Internet and Society at Harvard University, 2014. (Research Publication No. 2014-17). Disponível em: https://ssrn.com/abstract=2538813. Acesso em: 7 abr. 2021.

GEE, James Paul. New people in new worlds, the new capitalism and schools. In: COPE, Bill; KALANTIZIS, Mary (ed.). Multiliteracies: literacy, learning and the design of social futures. Melbourne: Macmillan, 2000. p. 43-68.

GIBSON, William. Neuromancer. São Paulo: Aleph, 1991.

HACHEM, Daniel Wunder; BONAT, Alan. O direito ao desenvolvimento de um projeto de vida na jurisprudência da Corte Interamericana de Direitos Humanos e a educação como elemento indispensável. Revista Opinião Jurídica, Fortaleza, v. 15, n. 21, p. 77-105, 2017.

ILLICH, Ivan. Deschooling Society. New York: Harper and Row, 1971.

JENKINS, Henry. Convergence Culture: where the old and new media colide. New York: New York University, 2009.

KEMP, Simon. Global Digital Overview 2020. [S. l.]: We are social, 2020. Disponível em: https://bit.ly/2Wd6ORx. Acesso em: 20 mar. 2020.

LAPA, Andrea Brandão. Reflexões sobre a formação crítica em redes sociais. In: BERGMANN, Juliana; GRANÉ, Mariona (org.). La universidad en la nube. 1. ed. Barcelona: Laboratori de Mitjans Interactius, 2013. p. 23-46. (Colecció Transmedia, v. 6). 
LAPA, Andrea Brandão; LACERDA, André Lopes; COELHO, Isabel Colucci; SCHWERTL, Simone Leal. Redes sociais como espaço alternativo para formação crítica. In: LAPA, Andrea; LACERDA, Andreson Lopes (org.). A Formação de sujeitos em espaços sociais virtuais. 1. ed. Rio de Janeiro: Letra Capital, 2018. p. 21-43.

LAPA, Andrea Brandão; PRETTO, Nelson De Luca. Inovar com os hackers na educação. In: DIAS, Paulo; MOREIRA, Darlinda; MENDES, António Quintas. Inovar para a qualidade na educação digital. Lisboa: Universidade Aberta de Portugal, 2019. p. 99-116. (Coleção Educação a Distância e eLearning, n. 6). Disponível em: https://bit.ly/3ASVhpN. Acesso em: 7 abr. 2021.

MACHADO, Arlindo. Arte e mídia. São Paulo: Zahar, 2007.

MALINI, Fábio. O Comunismo das redes sistema midiático P2P, colaboração em rede e novas políticas de comunicação na Internet. 2007. 333 f. Tese (Doutorado em Comunicação e Cultura) - Universidade Federal do Rio de Janeiro, Rio de Janeiro, 2007.

MARTÍN-BARBERO, Jesús. Globalização comunicacional e transformação cultural. In: MORAES, Dênis de (org.). Por uma outra comunicação: mídia, mundialização cultural e poder. 3. ed. Rio de Janeiro: Record, 2005. pp. 5786.

MARTÍN-BARBERO, Jesús. A comunicação na educação. São Paulo: Contexto, 2014.

MASSCHELEIN, Jan; MAARTEN, Simons. Em defesa da escola: uma questão pública. Belo Horizonte: Autêntica, 2017.

MENDONÇA, Ricardo. Se o país é rico, por que há tantos pobres? In: CANELA, Guilherme. Políticas públicas sociais e os desafios para o jornalismo. São Paulo: Cortez, 2008. p. 227-238.

MOZILLA FOUNDATION. The internet health report 2018. $\left[\begin{array}{llllll}S . & l .: & s . & n .\end{array}\right]$ 2018. Disponível em: https://bit.ly/3AUKxHp. Acesso em: 7 abr. 2021.

NOBRE, Gabriel P.; ALMEIDA, Jussara M.; FERREIRA, Carlos H. G. Caracterização de bots no Twitter durante as Eleições Presidenciais no Brasil em 2018. In: WORKSHOP BRASILEIRO DE ANÁLISE DE REDES SOCIAIS E MINERAÇÃO, 8. 2019, Porto Alegre. Anais [...]. Porto Alegre: SBC, 2019. p. 107-118. Disponível em: https://bit.ly/2WbZ6Yr. Acesso em: 20 mar. 2020.

NÓVOA, António. Nada será como antes. Revista Pátio, Porto Alegre, Ano XVII, n. 72, nov. 2014/jan. 2015. Disponível em: https://bit.ly/3sxC49Z. Acesso em: 20 mar. 2020.

OROZCO-GÓMEZ, Guillermo. Podemos ser mais criativos ao adotar a inovação tecnológica em educação? Uma proposta em comunicação. MATRIZes, São Paulo, v. 1, n. 1, p. 209-216, 2007. DOI: https://doi.org/10.11606/issn.1982-8160.v1ilp209-216. Disponível em: https://bit.ly/3k68FQI. Acesso em: 20 mar. 2020.

PAÍS estagnado: um retrato das desigualdades brasileiras. OXFAM Brasil, São Paulo, 27 nov. 2018. Disponível em: https://bit.ly/38d6G7H. Acesso em: 7 abr. 2021.

PARISER, Eli. The filter bubble: What the Internet is hiding from you. Penguin: Books Limited, 2011.

PRETTO, Nelson De Luca. Educações, Culturas e Hackers: escritos e reflexões. Salvador: EDUFBA, 2017.

PRETTO, Nelson De Luca; PINTO, Cláudio da Costa. Tecnologias e novas educações. Revista Brasileira de Educação, Campinas, v. 11, n. 31, p. 19-30, jan./abr. 2006. Disponível em: https://bit.ly/3kdp71D. Acesso em: 7 abr. 2021.

SANTOS Boaventura de Sousa. A difícil democracia: reinventar as esquerdas. São Paulo: Boitempo, 2016. 
SEN, Amartya. Desenvolvimento como liberdade. São Paulo: Companhia das Letras, 2000.

SHIRKY, Clay. A cultura da participação: criatividade e generosidade no mundo conectado. Rio de Janeiro: Zahar, 2011.

SIMON, Imre; VIEIRA, Miguel Said. O rossio não-rival. In: PRETTO, Nelson De Luca; SILVEIRA, Sérgio Amadeu da. Além das redes de colaboração: internet, diversidade cultural e tecnologias do poder. Salvador, Bahia: UFBA, 2008. p. 15-30.

SRNICEK, Nick. Capitalismo de Plataformas. Buenos Aires: Caja Negra, 2018.

UNIÃO NACIONAL DOS DIRIGENTES MUNICIPAIS DE EDUCAÇÃO. Pesquisa Undime sobre Volta às Aulas 2021. [Brasília]: Undime, 2021. Disponível em: https://bit.ly/3y3NNyr. Acesso em: 20 abr. 2021.

ZUBOFF, Shoshana. Big other: Surveillance capitalism and the prospects of an information civilization. Journal of Information Technology, [S. l.], v. 30, n. 1, p. 75-89, 2015. Disponível em: https://bit.ly/3z2rPwR. Acesso em: 20 mar. 2020.

ZUBOFF, Shoshana. Un capitalismo de vigilância: sua escova de dentes te espiona. Le Monde Diplomatique Brasil, [S. l.], Edição 138, p. 3-32, 3 jan. 2019. 